\title{
Dietary myristic acid modifies the HDL-cholesterol concentration and liver scavenger receptor BI expression in the hamster*
}

\author{
Carole Loison ${ }^{1}$, François Mendy ${ }^{2}$, Colette Sérougne ${ }^{1}$ and Claude Lutton ${ }^{1} \dagger$ \\ ${ }^{1}$ Laboratoire de Physiologie de la Nutrition (laboratoire associé à l' INRA), Université Paris-Sud, Centre d'Orsay, bâtiment \\ 447, 91405 Orsay Cedex, France \\ ${ }^{2}$ Résidence du parc de Béarn, 2, rue du calvaire, 92120 Saint-Cloud, France
}

(Received 27 February 2001 - Revised 27 November 2001 - Accepted 14 December 2001)

\begin{abstract}
The influence of myristic acid in a narrow physiological range $(0.5$ to $2.4 \%$ of total dietary energy) on the plasma and hepatic cholesterol metabolism was investigated in the hamster. The hamsters were fed on a diet containing $12.5 \mathrm{~g}$ fat $/ 100 \mathrm{~g}$ and $0.05 \mathrm{~g}$ cholesterol $/ 100 \mathrm{~g}$ with $0.5 \%$ myristic acid (LA diet) for 3 weeks (pre-period). During the following 3 weeks (test period), they were divided into four dietary groups with $0.5 \%$ (LA), $1.2 \%$ (LM), $1.8 \%$ (ML) or $2.4 \%(\mathrm{M})$ myristic acid. Finally, half the hamsters in each group were again fed the LA diet for another 3 weeks (post-period). At the end of the test period, the hepatic expression of the scavenger receptor BI (SR-BI) was lower in the LM, ML and M groups than in the LA group whereas the hepatic cholesteryl ester concentration was higher. Cholesterol $7 \alpha$ hydroxylase activity was lower in the ML and M groups than in the LA and LM groups while the sterol 27 hydroxylase and 3-hydroxy-3-methyl glutaryl coenzyme A reductase activities were not modulated by dietary myristic acid. This is the first time a negative correlation has been observed between the HDL-cholesterol concentration and the hepatic mass of SR-BI $(r-0.69 ; P<0.0001)$ under physiological conditions. An inverse linear regression was also shown between SR-BI and the percentage of myristic acid in the diet $(r-0.75 ; P<0.0001)$. The hepatic mass of SR-BI in the M group had increased at the end of the post-period compared with the test-period values. The present investigation shows that myristic acid modulates HDLcholesterol via a regulation of the SR-BI expression.
\end{abstract}

Myristic acid: HDL-cholesterol: Scavenger receptor class B type I: Hamster

Myristic acid is considered as the saturated fatty acid which induces the most important increase in plasma total cholesterol especially in LDL-cholesterol levels in human subjects or in animals (Hegsted et al. 1965; Hayes \& Khosla, 1992). In most of the studies which led to this conclusion, myristic acid represented a very high percentage of the total dietary energy: $16 \%$ in human subjects (Kris-Etherton \& Yu, 1997) or 16\% (Salter et al. 1998) to $20 \%$ (Woolett et al. 1992) in hamsters. Moreover, in these experimental diets, cholesterol is often present in inadequate doses (either none or too high) as reported by Nicolosi (1997). Under these conditions (far from physiological doses), myristic acid could alter cholesterol metabolism. However, myristic acid seems to be an important cell component since numerous proteins need to be myristoylated in order to play their biological role in the transduction pathway, vesicular trafficking and structural positioning (Boutin, 1997). Myristic acid is also found in significant levels in most mammalian milk and is mainly in the $s n-2$ position on the triacylglycerol (TG) molecule (Jensen et al. 1990). As suggested a few years ago (Berner, 1993), the impact of myristic acid (milk fat) on serum lipids needed to be re-evaluated using a more realistic mixed-fat diet. In human milk, myristic acid represents $9 \%$ of total fatty acids (about $3.4 \%$ of total energy) (Jensen, 1996). Since maternal milk is a well-balanced food, the hypothesis of the present study is that when myristic acid makes up to $9 \%$ of total fatty acids in the lipid part of the diet, it would have no undesirable effects on cholesterol metabolism.

\footnotetext{
Abbreviations: CYP27A1, sterol 27 hydroxylase; CYP7A1, cholesterol 7 $\alpha$ hydroxylase; HDL-C, HDL-cholesterol; HMGCoA-R, 3-hydroxy-3-methyl glutaryl coenzyme A reductase; LA, lard diet; LM, lard and milk fat diet; M, milk fat diet; ML, milk fat and lard diet; non-HDL-C, non-HDLcholesterol; SR-BI, scavenger receptor class B type I; SREBP, sterol regulatory element binding protein; TG, triacylglycerol.

* Supported by a CERIN grant.

$\dagger$ Corresponding author: Professor Claude Lutton, fax +33 1691570 74, email claude.lutton@ibaic.u-psud.fr
} 
Male golden Syrian hamsters were chosen to test this hypothesis because they have a well-established similarity with human cholesterol metabolism (Spady \& Dietschy, 1983) and are sensitive to changes in the composition of dietary fats (Spady \& Dietschy, 1988; Lindsey et al. 1990; Kris-Etherton \& Dietschy, 1997). They received semi-purified diets with low concentrations of cholesterol $(0.05 \%)$ and a lipid content $(12.5 \%)$, which represented $27 \%$ of the total dietary energy (i.e. generally advised for human nutrition by Grundy (1997)). Under these nutritional conditions, the percentage of myristic acid varies between $0.5 \%$ (i.e. generally found in human nutrition) and $2.4 \%$ (about $9 \%$ of total fatty acids in the diet) of total energy.

Since the liver is the main organ concerned with the regulation of cholesterol homeostasis, the major hepatic activities implicated in this process have to be assayed in order to better understand the role of myristic acid. The scavenger receptor class B type I (SR-BI) was shown to be an HDL receptor (Acton et al. 1996). This receptor, like the LDL receptor in man, plays a major role in cholesterolaemia regulation, especially in rodents (CombettesSouverain et al. 1999). However, only one study (Spady et al. 1999) has reported that saturated fatty acids modify the expression of SR-BI compared with polyunsaturated fatty acids. Dietary myristic acid could also modulate bile acid biosynthesis which is the major process of cholesterol degradation in man and animals and can occur via two important pathways (neutral and alternative; Vlahcevic et al. 1996). Some studies in other species than hamsters (mice and gerbils) have shown that dietary fatty acids are able to regulate bile acid biosynthesis (Cheema et al. 1997; Hajri et al. 1998b).

The purpose of the present study was to test the hypothesis that myristic acid ( 0.5 to $2.4 \%$ of total energy and mostly in the $s n-2$ position, as in maternal milk) has no undesirable effects on plasma cholesterol (particularly in the LDL fraction). The effects of dietary myristic acid on the lipid concentrations, masses of lipoprotein receptors (LDL-receptor, SR-BI) and activities of certain key enzymes of cholesterol and bile acid metabolism (3-hydroxy-3-methyl glutaryl coenzyme A reductase (HMGCoA-R), cholesterol $7 \alpha$ hydroxylase (CYP7A1), sterol 27 hydroxylase (CYP27A1)) in the liver were also observed.

\section{Materials and methods}

\section{Chemicals and isotopes}

Kits for cholesterol, triacylglycerol and phospholipid assays were purchased from Boehringer-Mannheim (Meylan, France) (CHOD-PAP and GPO-PAP methods), and from Wako Unipath (Dardilly, France). A rabbit polyclonal antibody against a peptide containing residues 495-509 from murine SR-BI (kindly prepared by André Mazur, Theix, France) was used to detect SR-BI as described by Acton et al. (1996). Hydroxymethylglutaryl coenzyme A, $\left[5-{ }^{3} \mathrm{H}\right]$ mevalonolactone, $\left[4-{ }^{14} \mathrm{C}\right]$ cholesterol and $\left[24-{ }^{14} \mathrm{C}\right]$ chenodeoxycholic acid were obtained from Dupont-NEN Products (Les Ulis, France). Emulsifier-safe was purchased from Packard Instrument Company (Meriden, CT, USA). Hydroxypropyl- $\beta$-cyclodextrin was kindly provided by Société Roquette frères (62 136 Lestrem, France).

\section{Animals and diets}

Five-week-old male golden Syrian hamsters (Mesocritus auratus) from our breeding unit designated LPN (Laboratoire de Physiologie de la Nutrition) were randomly assigned to four groups fed diets (Table 1) differing only in their lipid component (natural fat): LA (lard), M (milk fat), ML (milk fat+lard; 7:3) or LM (lard+milk fat; 6:4) containing myristic acid (C14:0) as $0.5,1.2,1.8$ or $2.4 \%$ of the total dietary energy respectively. The basal composition of these diets $(\mathrm{g} / 100 \mathrm{~g}$ total dry weight) was as follows: maize starch 34.95 , sucrose 20 , casein 20 , vitamin mix (see below) 2.5, salt mix (see below) 5 , cellulose 5 , cholesterol 0.05 , lipid 12.5 (natural fat $10+$ rapeseed oil-high oleic sunflower seed oil mix 2.5 (1:1)) which brought the minimum essential fatty acids.

The vitamin mix prepared on cellulose support contained ( $/ \mathrm{kg}$ diet): retinol $27 \mathrm{mg}$; ergocalciferol $2 \mathrm{mg}$; thiamin $50 \mathrm{mg}$; riboflavin $37.5 \mathrm{mg}$; calcium pantothenate $175 \mathrm{mg}$; pyridoxine $25 \mathrm{mg}$; meso-inositol $375 \mathrm{mg}$; vitamin $\mathrm{B}_{12}$ $0.125 \mathrm{mg}$; vitamin C $2000 \mathrm{mg}$; DL $\alpha$ tocopherol $425 \mathrm{mg}$; menadione $100 \mathrm{mg}$; nicotinic acid $250 \mathrm{mg}$; choline $3400 \mathrm{mg}$; folic acid $12.5 \mathrm{mg}$; biotin $0.75 \mathrm{mg}$; para-amino benzoic acid $125 \mathrm{mg}$; cellulose $17.37 \mathrm{mg}$.

The salt mix contained $(\mathrm{g} / \mathrm{kg}$ diet): $\mathrm{NaCl} 5 ; \mathrm{KCl} \mathrm{5}$; $\mathrm{CaHPO}_{4}$ 21.5; $\mathrm{MgCl}_{2} 2.5 ; \mathrm{MgSO}_{4} 2.5 ; \mathrm{Fe}_{2} \mathrm{O}_{3}$ 0.15; $\mathrm{FeSO}_{4} .7 \mathrm{H}_{2} \mathrm{O} \quad 0.25 ; \quad \mathrm{MnSO}_{4} \cdot \mathrm{H}_{2} \mathrm{O} \quad 0.1225 ; \quad \mathrm{CuSO}_{4} .5 \mathrm{H}_{2} \mathrm{O}$ $0.025 ; \mathrm{ZnSO}_{4} .7 \mathrm{H}_{2} \mathrm{O} \quad 0.1004 ; \mathrm{CoSO}_{4} .7 \mathrm{H}_{2} \mathrm{O} \quad 0.0002 ; \mathrm{KI}$ 0.0004, maize starch 12.851 .

The hamsters were individually caged and had free access to food and water. Lighting conditions were controlled according to a $12 \mathrm{~h}$ light $-12 \mathrm{~h}$ dark cycle $(7.00-$ 19.00 hours). The temperature was maintained at $25^{\circ} \mathrm{C}$.

The standard diet, vitamin mix and salt mix were purchased from UAR (Villemoisson, 91360 Epinay/orge France); lard (Orsay France); and milk fat 'huile de beurre fractionnée' were given by BESNIER BRIDEL (355240 Retiers France). All the experiments were conducted according to the French Regulations for Animal Experimentation (Art 19. Oct 1987, Ministry of Agriculture).

\section{Experimental design}

After weaning, the animals were fed on a standard diet (containing $5 \%$ lipids) for 2 weeks in order to homogenize their body weight before the experiment. The experiment was separated into three periods.

During the first 3-week experimental period (preperiod), the hamsters were fed on LA which contained $0.5 \%$ of total dietary energy as myristic acid. At the end of this period, the animals were slightly anaesthetized with an intramuscular injection of Tiletamine and Zolazepam (Zoletil 50, Virbac, Carros, France) at a dose of $50 \mathrm{mg} / \mathrm{kg}$ body weight and blood samples $(500 \mu \mathrm{l})$ were obtained by cardiac puncture, after an overnight fast. The plasma was separated from the blood cells by centrifugation 
Table 1. Fatty acid composition of the test diets* ( $\mathrm{g} / 100 \mathrm{~g}$ fatty acids)

\begin{tabular}{|c|c|c|c|c|c|c|c|c|}
\hline \multirow{2}{*}{$\begin{array}{l}\text { Test diets... } \\
\text { Fatty acids }\end{array}$} & \multicolumn{2}{|c|}{ LA } & \multicolumn{2}{|c|}{ LM } & \multicolumn{2}{|c|}{ ML } & \multicolumn{2}{|c|}{$M$} \\
\hline & $\mathrm{g} / 100 \mathrm{~g}$ & $\% †$ & $\mathrm{~g} / 100 \mathrm{~g}$ & $\% †$ & $\mathrm{~g} / 100 \mathrm{~g}$ & $\% †$ & $\mathrm{~g} / 100 \mathrm{~g}$ & $\% †$ \\
\hline$<\mathrm{C} 12: 0$ & 0.064 & 0.02 & $4 \cdot 34$ & $1 \cdot 2$ & $7 \cdot 6$ & $2 \cdot 1$ & $10 \cdot 8$ & 3 \\
\hline C12:0 & 0.11 & 0.03 & 1.44 & 0.4 & $2 \cdot 4$ & 0.7 & 3.4 & 0.9 \\
\hline C14:0 & $1 \cdot 81$ & 0.5 & $4 \cdot 4$ & $1 \cdot 2$ & 6.5 & $1 \cdot 8$ & 8.54 & $2 \cdot 4$ \\
\hline C16:0 & $21 \cdot 6$ & 6 & 19.6 & 5.4 & 18 & 5 & $16 \cdot 6$ & 4.6 \\
\hline C18:0 & 14 & 3.9 & $10 \cdot 6$ & 2.9 & 8.05 & $2 \cdot 2$ & 5.5 & 1.5 \\
\hline C18:1 & $46 \cdot 4$ & 12.9 & 43.2 & 12 & $41 \cdot 1$ & 11.4 & 39 & $10 \cdot 8$ \\
\hline C18:2 & $10 \cdot 2$ & $2 \cdot 8$ & 9.6 & $2 \cdot 65$ & 9.1 & 2.5 & 8.75 & $2 \cdot 4$ \\
\hline C18:3 & 1.45 & 0.40 & 1.45 & 0.40 & 1.45 & 0.40 & 1.45 & 0.40 \\
\hline SFA & 38.7 & $10 \cdot 7$ & $41 \cdot 7$ & $11 \cdot 6$ & 44 & $12 \cdot 2$ & $46 \cdot 3$ & $12 \cdot 9$ \\
\hline MUFA & $49 \cdot 6$ & $13 \cdot 8$ & 46.5 & $12 \cdot 9$ & $44 \cdot 2$ & $12 \cdot 3$ & 41.9 & 11.6 \\
\hline PUFA & 11.6 & 3.2 & $11 \cdot 1$ & 3.1 & $10 \cdot 6$ & 2.9 & $10 \cdot 2$ & $2 \cdot 8$ \\
\hline $\mathrm{P}: \mathrm{S}$ & 0.49 & & 0.43 & & 0.39 & & 0.36 & \\
\hline
\end{tabular}

LA, $10 \%$ lard $+2.5 \%$ rapeseed oil-high oleic sunflower seed oil mix (1:1); LM, $6 \%$ lard $+4 \%$ milk fat $+2.5 \%$ rapeseed oil-high oleic sunflower seed oil mix (1:1); ML, $7 \%$ milk fat $+3 \%$ lard $+2.5 \%$ rapeseed oil-high oleic sunflower seed oil mix (1:1); M, $10 \%$ milk fat $+2.5 \%$ rapeseed oil-high oleic sunflower seed oil mix (1:1); SFA, saturated fatty acids; MUFA, monounsaturated fatty acids; PUFA, polyunsaturated fatty acids; P:S, ratio of polyunsaturated fatty acids to saturated $(\mathrm{C} 12: 0+\mathrm{C} 14: 0+\mathrm{C} 16: 0)$ fatty acids.

${ }^{*}$ For details of the test diets, see p. 200.

† Values represent the part of individual fatty acid expressed as the percentage of total energy.

$\left(10 \mathrm{~min}\right.$ at $2600 \mathrm{~g}$, at $\left.4^{\circ} \mathrm{C}\right)$ and stored at $-20^{\circ} \mathrm{C}$ for further analysis (plasma lipids). During the second 3-week period (test period), each group received its corresponding diet: LA, LM, ML or M, and cardiac punctures were performed as above. Each group was then divided into two subgroups. The animals from the first subgroup were anaesthetized with an intramuscular injection of Tiletamine and Zolazepam (Zoletil 50, Virbac, Carros, France) at a dose of $100 \mathrm{mg} / \mathrm{kg}$ body weight and killed by heart blood puncture. The abdomen was opened by a midline incision and the liver was excised, weighed and samples were taken for lipid measurement, SR-BI receptor mass and enzymic assays. Hamsters from the second subgroup were again fed on LA (post-period) for 3 weeks and the same procedure used for the first subgroup was applied.

\section{Plasma and lipoproteins}

Plasma cholesterol, phospholipids and TG concentrations were measured by enzymic procedures using commercial kits. Apolipoprotein B containing lipoproteins VLDL and LDL was precipitated with phosphotungstate reagent (Weigand \& Daggy, 1990). The supernatant fraction was assayed for HDL-cholesterol (HDL-C) with commercial kits. The quantity of VLDL- and LDL-cholesterol (nonHDL-C) was calculated from the difference between plasma total cholesterol and HDL-C.

\section{Liver lipids}

Frozen liver samples $(0.5 \mathrm{~g})$ were thawed and homogenized in $5 \mathrm{ml}$ isopropanol, using an Ultra-Turrax apparatus (Janke \& Kunkel Gmb \& Co., Staufen, Germany). After incubation at $60^{\circ} \mathrm{C}$ for $1 \mathrm{~h}$ and centrifugation for $5 \mathrm{~min}$ at $3000 \mathrm{~g}$, the supernatant fraction was collected and the pellet was re-extracted with $5 \mathrm{ml}$ isopropanol. TG and total cholesterol were measured enzymically on pooled isopropanolic extracts, using appropriate kits. Free and esterified cholesterol were separated by TLC on silica gel plates eluted with diethyl ether, dried and dissolved in isopropanol before enzymic cholesterol determination.

\section{Hepatic enzyme activities}

The microsomal and mitochondrial fractions were isolated according to the procedure described by Einarsson et al. (1986) and Souidi et al. (1999). HMGCoA-R activity was determined in the microsomal fractions in the presence of alkaline phosphatase using Phillip \& Shapiro's (1979) radioisotopic technique. CYP7A1 was assayed in the microsomal fractions according to a radioisotopic method using $\left[4-{ }^{14} \mathrm{C}\right]$ cholesterol, solubilized and carried by hydroxypropyl- $\beta$-cyclodextrin (Souidi et al. 1998). CYP27A1 was assayed in the mitochondrial fractions according to a radioisotopic method using $\left[4-{ }^{14} \mathrm{C}\right]$ cholesterol, solubilized and carried by hydroxypropyl- $\beta$-cyclodextrin (Souidi et al. 1999).

\section{Scavenger receptor class B type I receptor binding}

Total membranes from frozen liver samples stored at $-80^{\circ} \mathrm{C}(1 \mathrm{~g})$ were prepared according to Kovanen et al. (1979). Membrane proteins were solubilized in a buffer containing Triton-X100 2\% (Schneider et al. 1982). They were then assayed by Lowry's method using bovine serum albumin as a standard. (Lowry et al. 1951)

Immunodetection was then carried out for SR-BI. Liver protein membranes were diluted in a dilution buffer (Trismaleate $125 \mathrm{~mm} ; \mathrm{CaCl}_{2} 2 \mathrm{~mm}$, aprotinin $200 \mathrm{IU} / \mathrm{ml}$; DTT $15 \mathrm{~mm}$; pH 6). Diluted samples $(2 \mu \mathrm{g}$ in $50 \mu \mathrm{l})$ were boiled for $5 \mathrm{~min}$ at $90^{\circ} \mathrm{C}$ and spotted onto a nitrocellulose membrane using a dot-blot apparatus (Bio-Rad, Richmond, 
Table 2. Body weights, dietary intake and liver weights at the end of the different dietary periods from hamsters fed on semi-purified diets containing different dietary fatty acids*

(Mean values and standard errors for sixteen, eighteen, sixteen or eighteen hamsters per group (pre- and test periods) and for eight, nine, seven or nine hamsters per group (post-period))

\begin{tabular}{|c|c|c|c|c|c|c|c|c|}
\hline \multirow[t]{2}{*}{ Test diets... } & \multicolumn{2}{|c|}{ LA } & \multicolumn{2}{|c|}{ LM } & \multicolumn{2}{|c|}{ ML } & \multicolumn{2}{|c|}{ M } \\
\hline & Mean & SEM & Mean & SEM & Mean & SEM & Mean & SEM \\
\hline \multicolumn{9}{|c|}{ Body weight (g) } \\
\hline Pre-period & $69 \cdot 3$ & $1 \cdot 8$ & $69 \cdot 7$ & $1 \cdot 2$ & $68 \cdot 3$ & 1.6 & $67 \cdot 3$ & $1 \cdot 1$ \\
\hline Test period & 79.5 & 1.5 & $79 \cdot 5$ & 1.4 & 79.5 & $1 \cdot 2$ & $78 \cdot 3$ & 1 \\
\hline Post-period & $84 \cdot 7$ & 2 & 84 & 1.6 & 83.9 & 1.6 & $84 \cdot 3$ & 2 \\
\hline \multicolumn{9}{|c|}{ Dietary intake $(\mathrm{g} / \mathrm{d})$} \\
\hline Pre-period & $5 \cdot 8$ & 0.2 & $5 \cdot 6$ & $0 \cdot 1$ & $5 \cdot 3$ & 0.2 & $5 \cdot 6$ & 0.2 \\
\hline Test period & $5 \cdot 8$ & 0.2 & $5 \cdot 6$ & $0 \cdot 1$ & $5 \cdot 7$ & 0.2 & 6 & 0.3 \\
\hline Post-period & $6 \cdot 4$ & 0.4 & $5 \cdot 3$ & 0.2 & $5 \cdot 9$ & 0.4 & $6 \cdot 2$ & 0.3 \\
\hline \multicolumn{9}{|c|}{ Liver Weight $(\mathrm{g}) \dagger$} \\
\hline Test period & 3.08 & 0.09 & $3 \cdot 2$ & $0 \cdot 1$ & $3 \cdot 3$ & 0.1 & 3.08 & 0.06 \\
\hline Post-period & $3 \cdot 1$ & 0.1 & $3 \cdot 2$ & 0.05 & $3 \cdot 4$ & 0.1 & $3 \cdot 4$ & 0.1 \\
\hline
\end{tabular}

${ }^{*}$ For details of diets and procedures, see Table 1 and p. 200.

†For this parameter, there were eight, nine, nine or nine hamsters per group (test period) and eight, nine, seven or nine hamsters per group (post-period).

CA). The nitrocellulose membranes were incubated in a quenching buffer containing $5 \%$ fat-free milk (Tris- $\mathrm{HCl}$ $25 \mathrm{~mm}$; $\mathrm{NaCl} 25 \mathrm{~mm} ; \mathrm{CaCl}_{2} 2 \mathrm{~mm}$, pH 8). The membranes were washed with Tween Tris buffered saline $(\mathrm{NaCl}$ $500 \mathrm{~mm}$; Tris-base $250 \mathrm{~mm}$; Tween 20, 0.05\%; pH 7.5) buffer and incubated for $90 \mathrm{~min}$ in the presence of the antibody against SR-BI diluted 1:2000 in an incubation buffer containing $0.1 \%$ fat-free milk (Tris- $\mathrm{HCl} 60 \mathrm{~mm} ; \mathrm{NaCl}$ $25 \mathrm{~mm} ; \mathrm{CaCl}_{2} 2 \mathrm{~mm}, \mathrm{pH}$ 8). The membrane was washed three times with Tween Tris buffered saline and was incubated for 90 min with anti-immunoglobulin antibodies conjugated with horseradish peroxidase diluted at 1:2000. The membranes were washed three times with Tween Tris buffered saline buffer, and incubated for $1 \mathrm{~min}$ with a chemiluminescence reagent (ECL, Amersham). The membranes were protected with a plastic film and the sensitive film was revealed in a dark room. The intensity of the spots was measured with a laser densitometer (ultroscan 2222 LKB, Sweden) and the relative SR-BI content in each spot was estimated by the peak height of the scan.

The linearity of the response as a function of the protein quantity spotted was checked. The specific antibodies raised against SR-BI gave a unique band in Western blots with apparent molecular weights of about $82 \mathrm{kD}$ (Milliat et al. 2000).

\section{Statistical analysis}

Results were given as mean values and their SEM. Statistical differences among the groups were determined by ANOVA followed by a Student-Newman-Keuls test. Differences between pre-period and test-period values (for cholesterol, phospholipid and TG concentrations) were analysed by a paired $t$ test in which individual animals served as their own controls. Differences between test-period and post-period values were analysed by a $t$ test. A value of $P<0.05$ was considered significant. The Spearman method (software package Statview 4.5 for Windows) was used to determine the correlations.

\section{Results \\ Physiological status}

The hamsters remained in good health throughout the experiment. Daily food intake, body weights and liver weights during the three experimental periods are reported in Table 2. There were no significant differences in these parameters between the four groups at the end of each experimental period.

\section{Plasma lipid concentrations}

Plasma lipid concentrations measured at the end of each dietary period are shown in Table 3 .

Test period. At the end of this period, plasma cholesterol levels increased in the LM, ML and M groups compared with the pre-period values. However, there were no significant differences between the four groups.

The plasma phospholipid levels increased in the LM, ML and M groups compared with the pre-period values but were lower in the LA group than in the other groups.

The plasma TG levels in the M and ML groups increased compared with the pre-period values. There were no significant differences between the four groups.

Post-period. Plasma cholesterol levels in the LM group decreased compared with the test-period values. Plasma cholesterol levels in the $\mathrm{M}$ group were higher than in the LA and LM groups. Plasma phospholipid levels in the LM group decreased compared with the test-period values. Plasma phospholipid levels in the $\mathrm{M}$ group were higher than in the LA and LM groups. The plasma TG concentrations in the four groups were similar to those of the test period. No differences were observed between the four groups.

\section{Lipoprotein cholesterol concentrations}

Plasma HDL-C and non HDL-C concentrations measured at the end of each dietary period are shown in Table 4.

Test period. The plasma HDL-C concentrations 
Table 3. Plasma lipid concentrations at the end of the different dietary periods from hamsters fed on semi-purified diets containing different dietary fatty acids*

(Mean values and standard errors for thirteen, sixteen, thirteen or seventeen hamsters per group (pre- and test periods) and for eight, nine, six or nine hamsters per group (post-period))

\begin{tabular}{|c|c|c|c|c|c|c|c|c|}
\hline \multirow{2}{*}{$\begin{array}{l}\text { Test diets... } \\
\text { Serum parameter }\end{array}$} & \multicolumn{2}{|c|}{ LA } & \multicolumn{2}{|c|}{ LM } & \multicolumn{2}{|c|}{ ML } & \multicolumn{2}{|c|}{ M } \\
\hline & Mean & SEM & Mean & SEM & Mean & SEM & Mean & SEM \\
\hline \multicolumn{9}{|l|}{ Cholesterol (mmol/l) } \\
\hline Pre-period & 3.59 & 0.10 & $3 \cdot 20$ & $0 \cdot 10$ & 3.69 & 0.13 & $3 \cdot 88$ & 0.10 \\
\hline Test period & $3 \cdot 90$ & 0.23 & $4 \cdot 32 \dagger$ & 0.15 & $4.42 \dagger$ & 0.21 & 4.49† & 0.18 \\
\hline Post-period & $3 \cdot 67^{\mathrm{a}}$ & $0 \cdot 10$ & $3 \cdot 75^{a} \neq$ & $0 \cdot 18$ & $3.95^{a, b}$ & 0.15 & $4.45^{\mathrm{b}}$ & 0.23 \\
\hline \multicolumn{9}{|c|}{ Phospholipids (mmol/l) } \\
\hline Pre-period & $4 \cdot 26$ & 0.13 & 3.79 & 0.09 & 3.97 & 0.10 & 4.02 & 0.09 \\
\hline Test period & $3.79^{a}$ & 0.14 & $4.56^{\mathrm{b}} \dagger$ & $0 \cdot 14$ & $4.60^{\mathrm{b}} \dagger$ & 0.24 & $4.69^{b} \dagger$ & 0.21 \\
\hline Post-period & $3.97^{\mathrm{a}}$ & 0.09 & $3.88^{a} \neq$ & 0.07 & $4 \cdot 17^{\mathrm{b}}$ & 0.13 & $4 \cdot 39^{b}$ & 0.15 \\
\hline \multicolumn{9}{|c|}{ Triacylglycerols (mmol/l) } \\
\hline Pre-period & 1.48 & 0.27 & 1.22 & $0 \cdot 11$ & 0.85 & 0.13 & $0 \cdot 81$ & 0.08 \\
\hline Test period & $1 \cdot 24$ & 0.20 & $1.55 \dagger$ & $0 \cdot 19$ & $1 \cdot 14$ & $0 \cdot 10$ & $1.40 \dagger$ & 0.15 \\
\hline Post-period & $1 \cdot 15$ & 0.13 & 1.38 & 0.17 & 0.95 & 0.11 & 1.25 & 0.18 \\
\hline
\end{tabular}

a,b Mean values within a row with unlike superscript letters were significantly different as determined by ANOVA followed by a Student-Newman-Keuls test $(P<0.05)$.

${ }^{*}$ For details of diets and procedures, see Table 1 and p. 200.

† Mean values for the test period were significantly different from those of the pre-period values $(P<0.05)$.

$\ddagger$ Mean values for the post period were significantly different from those of the test period values $(P<0.05)$.

increased in the LM, ML and M groups compared with the pre-period values. No significant difference in the HDL-C could be observed between the four groups. However, a linear regression $(r \quad 0.49, \quad P=0.01, n$ 23, $y=2.57+0.51 x$ ) was found between the percentage of myristic acid in the diets and the plasma HDL-C concentrations.

Non-HDL-C decreased in the $\mathrm{M}$ group compared with the pre-period values. There was no significant difference in non-HDL-C between the four groups at the end of the test period. There was no significant regression between the percentage of myristic acid in the diets and the plasma non-HDL-C concentrations.

Post-period. The plasma HDL-C concentrations decreased only in the ML group compared with the testperiod values. However, there were no significant differences between the four groups. Non-HDL-C decreased in the LA group compared with the test-period values. Non-HDL-C was lower in the LA group than in the ML and M groups.

\section{Hepatic cholesterol concentrations}

The hepatic free, ester, and total cholesterol concentrations measured at the end of each dietary period are shown in Table 5 .

Test-period. Total and cholesteryl ester concentrations in the $\mathrm{LM}, \mathrm{ML}$ and $\mathrm{M}$ groups were higher than in the LA group. Moreover, a linear regression $(r$ 0.60, $P<0.0001, n$ $35, y=9 \cdot 2+7 \cdot 8 x$ ) was found between the percentage of myristic acid in the diets and the hepatic cholesteryl ester concentrations. Free cholesterol concentrations in the $\mathrm{M}$ group were higher than in the LA group.

Table 4. Cholesterol lipoprotein concentrations at the end of the different dietary periods from hamsters fed on semi-purified diets containing different dietary fatty acids*

(Mean values and standard errors for nine, seven, five or eight hamsters per group (pre-period) and for five, seven, six or five hamsters per group (test period) and for five, seven, five or seven hamsters per group (post-period))

\begin{tabular}{|c|c|c|c|c|c|c|c|c|}
\hline \multirow[t]{2}{*}{ Test diets... } & \multicolumn{2}{|c|}{ LA } & \multicolumn{2}{|c|}{ LM } & \multicolumn{2}{|c|}{$\mathrm{ML}$} & \multicolumn{2}{|c|}{ M } \\
\hline & Mean & SEM & Mean & SEM & Mean & SEM & Mean & SEM \\
\hline \multicolumn{9}{|c|}{ HDL-cholesterol (mmol//) } \\
\hline Pre-period & $2 \cdot 23$ & 0.16 & 1.96 & 0.13 & $2 \cdot 17$ & 0.20 & $2 \cdot 31$ & 0.10 \\
\hline Test period & $2 \cdot 77$ & 0.31 & $3.22 \dagger$ & 0.15 & $3.58 \dagger$ & 0.32 & $3.70 \dagger$ & 0.26 \\
\hline Post-period & $2 \cdot 87$ & 0.21 & $2 \cdot 82$ & 0.18 & $2.64 \ddagger$ & 0.13 & 3.18 & 0.15 \\
\hline \multicolumn{9}{|c|}{ Non-HDL-cholesterol (mmol/l) } \\
\hline Pre-period & 1.36 & 0.05 & 1.06 & $0 \cdot 10$ & 1.63 & 0.15 & 1.50 & 0.07 \\
\hline Test period & 1.32 & 0.21 & 1.33 & $0 \cdot 10$ & $1 \cdot 37$ & 0.36 & $1.06 \dagger$ & 0.13 \\
\hline Post-period & $0.72^{\mathrm{a}} \ddagger$ & 0.05 & $1 \cdot 03^{a, b}$ & 0.15 & $1 \cdot 33^{\mathrm{b}}$ & 0.05 & $1.43^{\mathrm{b}}$ & 0.13 \\
\hline
\end{tabular}

${ }^{\mathrm{a}, \mathrm{b}}$ Mean values within a row with unlike superscript letters were significantly different as determined by ANOVA followed by a Student-Newman-Keuls test $(P<0.05)$.

${ }^{*}$ For details of diets and procedures, see Table 1 and p. 200.

† Mean values for the test period were significantly different from those of the pre-period values $(P<0.05)$.

$\ddagger$ Mean values for the post-period were significantly different from those of the test-period values $(P<0.05)$. 
Table 5. Hepatic cholesterol concentrations at the end of the different dietary periods from hamsters fed on semi-purified diets containing different dietary fatty acids*

(Mean values and standard errors for eight, nine, nine or nine hamsters per group (test period) and for eight, nine, seven or nine hamsters per group (post-period))

\begin{tabular}{|c|c|c|c|c|c|c|c|c|}
\hline \multirow[t]{2}{*}{ Test diets... } & \multicolumn{2}{|c|}{ LA } & \multicolumn{2}{|c|}{ LM } & \multicolumn{2}{|c|}{ ML } & \multicolumn{2}{|c|}{ M } \\
\hline & Mean & SEM & Mean & SEM & Mean & SEM & Mean & SEM \\
\hline \multicolumn{9}{|c|}{ Total cholesterol (mg/g liver) } \\
\hline Test period & $15 \cdot 2^{\mathrm{a}}$ & $3 \cdot 2$ & $23.9^{b}$ & $2 \cdot 6$ & $25 \cdot 5^{\mathrm{b}}$ & $1 \cdot 8$ & $32 \cdot 6^{b}$ & 2.5 \\
\hline Post-period & $17 \cdot 4$ & $2 \cdot 4$ & $22 \cdot 7$ & 3.6 & $22 \cdot 2$ & $3 \cdot 3$ & 28.4 & 3.7 \\
\hline \multicolumn{9}{|c|}{ Free cholesterol (mg/g liver) } \\
\hline Test period & $2 \cdot 6^{a}$ & 0.4 & $3 \cdot 2^{\mathrm{a}, \mathrm{b}}$ & 0.2 & $3 \cdot 7^{\mathrm{a}, \mathrm{b}}$ & 0.3 & $4 \cdot 2^{b}$ & 0.4 \\
\hline Post-period & 2.9 & 0.1 & $3 \cdot 4$ & 0.3 & 3.4 & 0.5 & 3.6 & 0.2 \\
\hline \multicolumn{9}{|c|}{ Esterified cholesterol (mg/g liver) } \\
\hline Test period & $12 \cdot 3^{\mathrm{a}}$ & $2 \cdot 9$ & $20 \cdot 8^{b}$ & $2 \cdot 4$ & $21 \cdot 7^{\mathrm{b}}$ & $1 \cdot 7$ & $28 \cdot 4^{\mathrm{b}}$ & $2 \cdot 2$ \\
\hline Post-period & $14 \cdot 3$ & $2 \cdot 3$ & $19 \cdot 3$ & $3 \cdot 3$ & $18 \cdot 8$ & 2.9 & 24.8 & 3.5 \\
\hline
\end{tabular}

Post-period. Hepatic cholesterol concentrations measured at the end of this period were similar to those obtained at the end of the test period. The cholesteryl ester, total or free cholesterol concentrations were the same in the four groups.

\section{Hepatic enzyme activities}

Hepatic CYP7A1 and CYP27A1 activities assayed at the end of each dietary period are shown in Fig. 1.

Test period. At the end of this period, no significant differences in the hepatic enzyme HMGCoA-R activity were found between the four groups (LA: 259 (SEM 26) ( $n$ 6), LM: 275 (SEM 20) ( $n$ 9), ML: 287 (SEM 22) ( $n$ 9), M: 258 (SEM 16) ( $n$ 9) pmol/min per whole liver).

Hepatic CYP7A1 activity in the LA and LM groups was higher than in the ML and M groups and a negative linear regression $(r-0.53, P=0.001, n 33, y=37.4-8.7 x)$ was found between the percentage of myristic acid in the diets and the hepatic CYP7A1 activities.

No significant difference in the CYP27A1 activity was found between the four groups. No significant regression between the percentage of myristic acid in the diets and the hepatic CYP27A1 activities was observed.

Post-period. CYP7A1 activity in the LA and LM groups decreased compared with the test-period values. There were no significant differences in the CYP7A1 and CYP27A1 activities between the four groups.

\section{Scavenger receptor class $B$ type I receptor mass}

The hepatic SR-BI receptor mass assayed at the end of each dietary period is shown in Fig. 2.

Test-period. The SR-BI mass was higher in the LA group than in the other groups. The SR-BI mass in the LM and ML groups was higher than in the M group.

Post-period. The SR-BI mass increased in the M group compared with the test-period values. No significant difference was found between the four groups.

Two correlations were found with the SR-BI mass. The first correlation between the hepatic SR-BI mass and plasma HDL-C $(r-0.69, P<0.0001, n$ 38) is represented in Fig 3(a). The second correlation between the hepatic SR-BI mass and hepatic cholesteryl ester concentration $(r-0.56, P<0.0001, n 55)$ is represented in Fig. 3(b).

A linear regression between the hepatic SR-BI mass and the percentage of myristic acid in the diet was found at the end of the test period $(r-0.75, P<0.0001, n 35)$ and is represented in Fig. 3(c).

\section{Discussion}

At the beginning of the experiment, the hamsters were fed on a semi-purified diet $(12.5 \%$ lipid) which contained a low myristic acid level $(0.5 \%$ of the total dietary energy). This period, called the pre-period, allowed the young animals which are usually fed on a chow diet $(5 \%$ lipid) to adapt their cholesterol metabolism. Blood samples collected at the end of this period enabled certain plasma parameters to have individual control values as is currently carried out in other species such as monkeys (Khosla et al. 1997) or man (Snook et al. 1999). After this adaptation period, the hamsters were fed on experimental diets for 3 weeks: LA ( $0.5 \%$ myristic acid), LM (1.2\% myristic acid), ML ( $1.8 \%$ myristic acid) or $\mathrm{M}$ ( $2.4 \%$ myristic acid). At the end of this test period, plasma cholesterol concentrations increased in the LM, ML and M groups compared with control values. The increase observed in these groups probably reflected the influence of higher percentages of myristic acid in the diet. However, this increase in the plasma cholesterol level observed in the M, ML and LM groups at the end of the test period was not sufficient to observe significant differences in this parameter between the four dietary groups. Our data show that the changes in plasma cholesterol concentration in response to dietary myristic acid concentration are smaller than those reported earlier in man (Hegsted et al. 1965; Keys \& Parlin, 1966; Mensink, 1993) or in animals for example, (hamsters and guinea-pigs; Nicolosi, 1997). The distribution of cholesterol among the different lipoprotein classes was also determined in the four dietary groups of our experiment. Although the important difference between the animals 

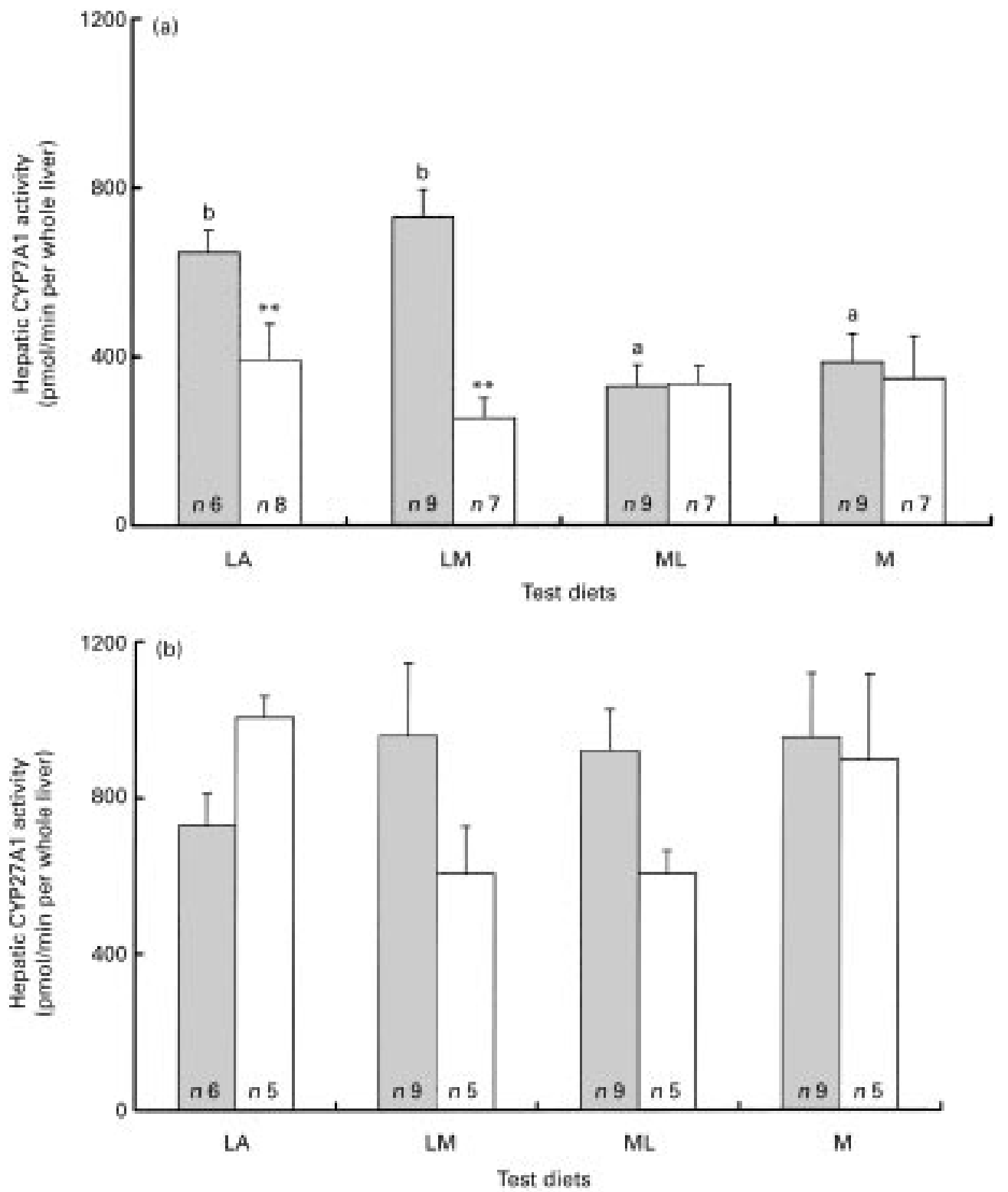

Fig. 1. Hepatic enzyme activities from hamsters fed on semi-purified diets containing different dietary fatty acids: LA (lard), LM (lard and milk fat, 6:4), ML (milk fat and lard, 7:3), M (milk fat) during the test period ( $\square$ ) and the post-period ( $\square$ ). Vertical bars represent standard errors of the mean. Mean values within each period with unlike superscript letters were significantly different as determined by ANOVA followed by a Student-Newman-Keuls test $(P<0.05)$. Mean values for the post-period were significantly different from those of the test-period values: ${ }^{\star \star} P<0.05$. CYP7A1, cholesterol $7 \alpha$ hydroxylase; CYP27A1, cholesterol 27 hydroxylase.

fed a low myristic acid level diet (LA: HDL-C $=2.77$ (SEM 0.31) $\mathrm{mmol} / \mathrm{l}$ ) and those fed a higher one (M: $\mathrm{HDL}-\mathrm{C}=3.70($ SEM 0.26$) \mathrm{mmol} / \mathrm{l})$ was not statistically significant, a linear regression between plasma HDL-C and the percentage of myristic acid in the diet $(r 0.49$, $P=0.01, n 23)$ was clearly established. This type of effect was not observed on the plasma non-HDL-C concentration. On the contrary, this latter parameter decreased in the hamsters fed the $\mathrm{M}$ diet (higher level of myristic acid) compared with their pre-period values. These results are noteworthy since in previous animal studies (Hajri et al. 1998a; Salter et al. 1998; Spady et al. 1999) or in man (Temme et al. 1997), dietary myristic acid increased not only the plasma HDL-C concentration but also those of plasma LDL-cholesterol. In some of the studies where natural fats were used, a disturbing effect of other saturated fatty acids present in the diet such as lauric acid in the coconut oil or palmitic acid in the palm oil cannot be excluded. As speculated by Tholstrup et al. (1994), the effects of myristic acid on plasma cholesterol should be added to those of lauric or palmitic acids (considered as hypercholesterolaemic). In this case, it became difficult to evaluate the specific action of myristic acid. Previous studies (Horton et al. 1993; Tsai et al. 1999) have demonstrated that a strong variation in the lauric acid composition of the diets, which is not the case in the present 


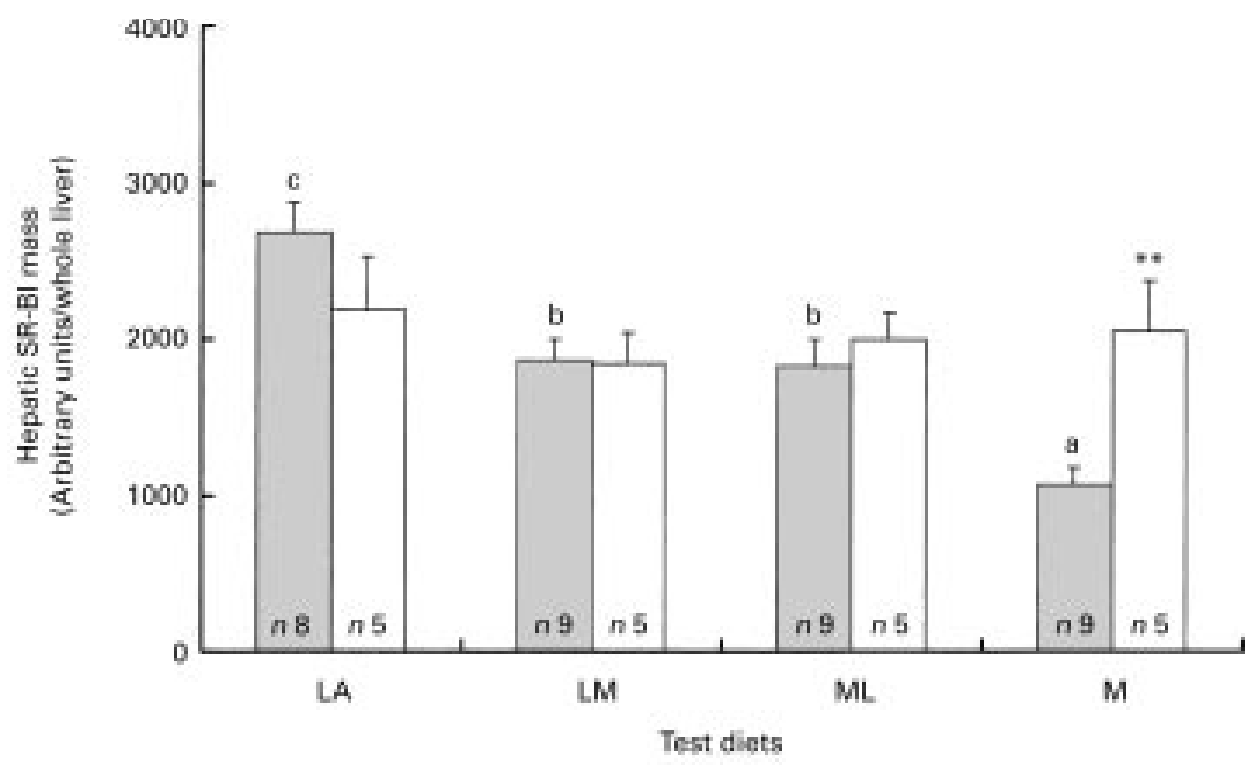

Fig. 2. Hepatic scavenger receptor class B type I (SR-BI) receptor mass from hamsters fed on semi-purified diets containing different dietary fatty acids: LA (lard), LM (lard and milk fat, 6:4), ML (milk fat and lard, 7:3, M (milk fat) during the test period ( $\square$ ) and the post-period ( $\square$ ). Vertical bars represent standard errors of the mean. Mean values within each period with unlike superscript letters were significantly different as determined by ANOVA followed by a Student-Newman-Keuls test $(P<0 \cdot 05)$. Mean values for the post-period were significantly different from those of the test-period values: ${ }^{\star \star} P<0.05$ ).

study (Table 1), is necessary to induce a modification in the plasma cholesterol concentration. Moreover, in the present study, the increase in HDL-C in the $\mathrm{M}$ group compared with the LA group can not be attributed to variations in the palmitic acid level (Table 1), since the proportion of this fatty acid is lower in the $\mathrm{M}$ group than in the LA group. Table 1 also shows that the proportions of the other fatty acids $(<\mathrm{C} 12: 0, \mathrm{C} 18: 0$ or $\mathrm{C} 18: 1)$ vary between the four test diets. However, it has already been demonstrated that these fatty acids have no real effects on the plasma cholesterol concentrations (Grundy, 1994; Kris-Etherton \& Yu, 1997; Nicolosi, 1997). Finally, in the present study the proportion of linoleic acid which along with myristic acid governs the plasma cholesterol response (Hayes \& Khosla, 1992) did not vary excessively and less drastically than the proportion of myristic acid between the test diets.

In the light of these obervations, the effects on cholesterolaemia (increase in the HDL-C) can mainly be attributed to the action of myristic acid.

Previous studies have shown that the position of palmitic acid on the TG molecule ( $s n$ position) influences lipoprotein metabolism (Innis et al. 1993; Zock et al. 1995; Nelson \& Innis, 1999). The majority of the myristic acid present in the milk-fat diets was in the $s n-2$ position (Jensen et al. 1990). By contrast, in previous studies using coconut oil (Spady \& Dietschy, 1988; Hajri et al. 1998a; Spady et al. 1999), there was a low proportion of myristic acid in the $s n-2$ position and a high level of lauric acid in this position (Small, 1991). This could further explain the differences observed between the previous studies (increase in LDL-cholesterol and HDL-C) and the present one (increase in HDL-C alone). These observations suggest that the environment of myristic acid in the diet (absence or presence of other saturated fatty acids), the position of myristic acid on the TG molecule and the percentage of this fatty acid in the diet could modulate its effects on lipoprotein metabolism.

It is generally accepted that variations in the plasma HDL-cholesterol and apolipoprotein AI levels are controlled not by the rate of their production but by the rate of their elimination (Rader \& Maugeais, 2000). This latter mechanism is controlled by two major proteins. The first, ATP-binding cassette 1 facilitates the transport of cholesterol between the peripheral cells and the nascent HDL particles (Fielding \& Young, 1999). The second, SRBI mediates the selective hepatic uptake of the cholesteryl ester of mature HDL particles (Acton et al. 1996). A negative correlation was observed between the hepatic mass of SR-BI and the plasma HDL-C concentration (Fig. 3(a)). These data were consistent with those observed in mice which overexpressed SR-BI (decrease of HDL-C) (Kosarsky et al. 1997; Wang et al. 1998) or in transgenic mice in which the expression of SR-BI was attenuated by $50 \%$ (increase of HDL-C) (Rigotti et al. 1997; Varban et al. 1998). However, to our knowledge, it is the first time that such a correlation was obtained under physiological conditions, with genetically unmodified animals. Another interesting linear inverse regression between the hepatic SR-BI mass and the percentage of myristic acid in the diet was also established (Fig. 3(c)). Spady et al. (1999) have recently shown that in hamsters a diet rich in polyunsaturated fatty acids increased the SR-BI expression compared with a diet rich in saturated fatty acids ( $8 \%$ myristic acid). The present study shows that increasing the amount of myristic acid in the diet is the most important factor in the increase of HDL-C concentration and that this effect is linked to a decrease in the amount of SR-BI in the liver.

Numerous nuclear factors are involved in the regulation 

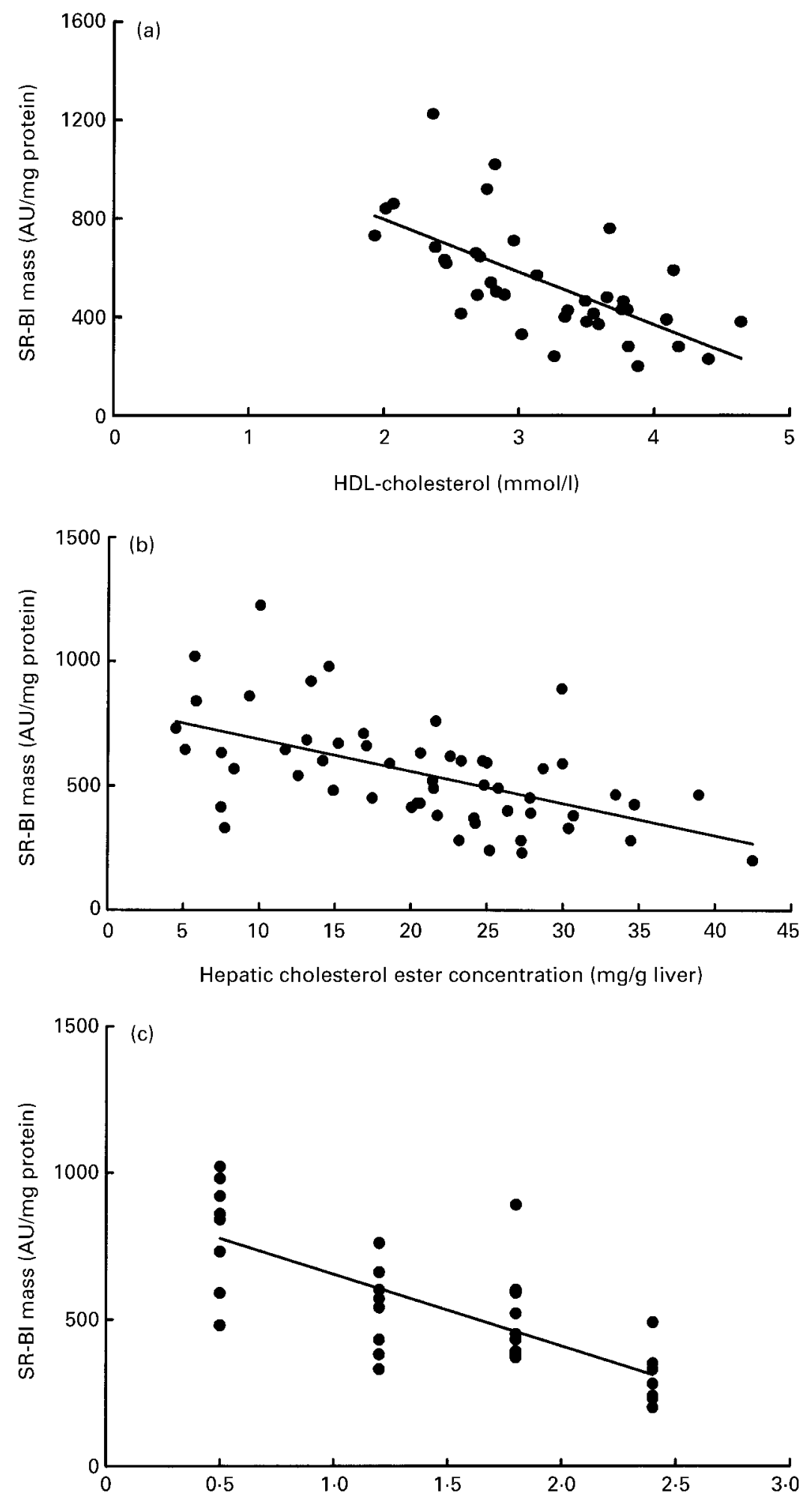

Dietary myristic acid (\% energy)

Fig. 3. Correlation between the hepatic scavenger receptor class B type I (SR-BI) mass and plasma HDL-cholesterol (a), and the hepatic cholesteryl ester concentration (b) during the test and post-periods. Linear regression between the hepatic SR-BI mass and the percentage of myristic acid in the four diets (LA, lard; LM, lard and milk fat (6:4); ML, milk fat and lard (7:3); M, milk fat) during the test-period (c). Each point represents the value obtained from a single animal. For (a), the correlation was characterized by $r-0.69 ; P<0.0001, n 38, y=1221.3-$ $213.54 x$. For (b), the correlation was characterized by $r-0.56$; $P<0.0001, n 55, y=814.3-12.85 x$. For (c), the regression was characterized by $r-0.75 ; P<0.0001 ; n 35, y=898.7-244.6 x$. AU, arbitrary units. 
of the SR-BI gene (Lopez \& McLean, 1999; Mizutani et al. 2000). More specifically, three forms of sterol regulatory element binding protein (SREBP), SREBP1-a, SREBP1-c, and SREBP2 are expressed in the liver and their truncated forms activate the transcription of the sterol-regulated gene (Brendel et al. 1998). Lopez \& McLean (1999) have observed that SREBPla bind to the promoter of the rat SR-BI gene. Worgall et al. (1998) have shown in vitro that some fatty acids decreased the level of mature SREBP. These authors also suggested that this effect of fatty acid is linked to an increase in the intracellular cholesterol pool. The present study supports this hypothesis since a negative correlation between the hepatic mass of SR-BI and the hepatic cholesteryl ester concentration (Fig 3(b)) was observed.

Newly synthesized cholesterol or that brought to the liver by the lipoproteins is mainly eliminated by its transformation into bile acids (Lutton, 1990). The hepatic CYP7A1 activity (rate-limiting enzyme of the neutral biosynthesis pathway) is higher in the LM and LA groups (low in myristic acid) than in the ML and M groups (high in myristic acid). These results agree with those of Hajri et al. (1998b) in gerbils. The authors observed a decrease in the CYP7A1 activity in gerbils fed a coconut-oil diet ( $8 \%$ myristic acid) compared with those fed a safflower-seed-oil diet (0\% myristic acid). The mechanism by which fatty acids are able to regulate CYP7A1 activity in vivo is unknown. Nevertheless, a recent in vitro study (Cheema \& Agellon, 2000) has shown that the CYP7A1 gene can be regulated by fatty acids via the peroxisome proliferator receptor $\alpha$. However, fatty acids influenced the CYP7A1 gene differently according to in vitro (Cheema \& Agellon, 2000) or in in vivo conditions (Cheema \& Agellon, 1999). Therefore, Cheema et al. (2000) suggested as others have (Marrapodi \& Chiang, 2000; Patel et al. 2000) that other nuclear factors and/or cofactors could compete with peroxisome proliferator receptor $\alpha$ for the regulation of the CYP7A1 gene. In contrast to the CYP7A1 activity, there was no difference in the CYP27A1 activity (main enzyme of the alternative pathway of bile acid biosynthesis) between the four dietary groups. Some studies (Kushawa et al. 1995; Chen et al. 1998) have observed the effects of a high-fat high-cholesterol diet on the CYP27A1 expression in monkeys. However there are no data concerning the eventual effect of a specific fatty acid. There is no significant difference in the activity of HMGCoA-R (the rate-limiting enzyme of cholesterol biosynthesis) between the four groups in our experiment. This effect was also shown in other studies with diets containing cholesterol and different fatty acid (myristic+lauric $v$. linoleic acids or trimyristin $v$. triolein) (Spady \& Dietschy, 1988; Bennet et al. 1995).

At the end of the test period, the remaining hamsters in each group returned to a low-myristic diet (LA) for 3 weeks. This post-period was required to test an eventual reversal in the major effects of dietary myristic acid observed at the end of the test period. At the end of this post-period, the plasma HDL-C concentration in the M group (higher in myristic acid) decreased but not significantly compared with the test-period values. However, this decrease is sufficient to abolish the difference between this group and the LA group (lower in myristic acid) observed at the end of the test period. It is noteworthy that, with regards to HDL-C, the mass of hepatic SR-BI in the $\mathrm{M}$ group was restored to a value similar to the one observed in the LA group (group in which myristic acid (0.5\%) did not vary during the three experimental periods). At the end of the post-period, the hepatic cholesteryl ester concentration in the $\mathrm{M}$ group did not completely return to a value similar to the one measured in the LA group. However, this decrease is sufficient to abolish the difference observed between these two groups at the end of the testperiod. These observations support our hypothesis that myristic acid is the main modulator of SR-BI expression and that the hepatic cholesteryl ester concentration is involved in this regulation via a mechanism implicating SREBP or other transcription factors.

In conclusion, the results obtained in the present study show for the first time that myristic acid increases HDL-C alone. Given the atheroprotective role of HDL (Stein \& Stein, 1999; Von Eckardstein \& Assmann, 2000), it will be interesting to confirm this effect in human subjects. The present paper also demonstrates the importance of myristic acid in the regulation of HDL-C via SR-BI in the hamster.

\section{Acknowledgements}

The authors thank Dr M. Parquet for scientific discussion, C. Verneau for technical assistance and N. Samson for animal care.

\section{References}

Acton S, Rigotti A, Landschulz KR, Xu S, Hobbs H \& Krieger M (1996) Identification of scavenger receptor SR-B1 as high-density lipoprotein receptor. Science 271, 518-520.

Bennet AJ, Billett MA, Salter AM, Mangiapane EH, Bruce JS, Anderton KL, Marenah CB, Lawson N \& White DA (1995) Modulation of hepatic apolipoprotein B, 3 hydroxy-3-methylglutaryl-coA reductase and low density lipoprotein receptor mRNA and plasma lipoprotein concentrations by defined dietary fats. Biochemical Journal 311, 167-173.

Berner LA (1993) Roundtable discussion on milk fat, Dairy foods, and coronary heart disease risk. Journal of Nutrition 123, 1175-1184.

Boutin J (1997) Myristoylation. Cell Signal 91, 15-35.

Brendel C, Fruchart JC, Auwerx J \& Schoonjans K (1998) Régulation transcriptionnelle du métabolisme du cholesterol (Transcriptional regulation of Cholestrol metabolism). Médecine/ Sciences 15, 56-62.

Cheema SK \& Agellon LB (1999) Metabolism of cholesterol is altered in the liver of $\mathrm{C} 3 \mathrm{H}$ mice fed fats enriched with different C18 fatty acids. Journal of Nutrition 129, 1718-1724.

Cheema SK \& Agellon LB (2000) The murine and human cholesterol $7 \alpha$ hydroxylase gene promoters are differentially responsive to regulation by fatty acids mediated via peroxisome proliferator activated receptor $\alpha$. Journal of Biochemical Chemistry 275, 12530-12536.

Cheema SK, Cikaluk D \& Agellon LB (1997) Dietary fats modulate the regulatory potential of dietary cholesterol on cholesterol $7 \alpha$-hydroxylase gene expression. Journal of Lipid Research 38, 315-328.

Chen LD, Kushwaha RS, Rice KS, Carey KD \& McGill HC 
(1998) Effect of dietary lipids on hepatic and extrahepatic sterol 27-hydroxylase activity in high- and low-responding baboons. Metabolism 47, 731-738.

Combettes-Souverain M, Milliat F, Sérougne C, Férézou J \& Lutton C (1999) SR-BI et métabolisme du cholestérol (SR-BI and cholesterol metabolism). Médecine/Sciences 15, 1252-1258.

Einarsson K, Angelin B, Ewerth S, Nilsell K \& Björkhem I (1986) Bile acid synthesis in man: assay of hepatic microsomal cholesterol $7 \alpha$-hydroxylase activity by isotope dilution-mass spectrometry. Journal of Lipid Research 27, 82-88.

Fielding CJ \& Young SG (1999) The ABCs of cholesterol efflux. Nature Genetics 22, 316-318.

Grundy SM (1994) Influence of stearic acid on cholesterol metabolism relative to other long-chain fatty acids. American Journal of Clinical Nutrition 60, 986-990.

Grundy SM (1997) What is the desirable ratio of saturated, polyunsaturated and monounsaturated fatty acid in the diet? American Journal of Clinical Nutrition 66, 988S-990S.

Hajri T, Khosla P, Pronczuk A \& Hayes KC (1998a) Myristic acid-rich fat raises plasma LDL by stimulating LDL production without affecting fractional clearance in gerbils fed a cholesterol-free diet. Journal of Nutrition 128, 477-484.

Hajri T, Pronzuk A \& Hayes KC (1998b) Linoleic acid rich diet increases hepatic taurine and cholesterol 7 alpha hydroxylase activity in conjunction with altered bile acid composition and conjugation in gerbils. Journal of Nutrition Biochemistry $\mathbf{9}$, 249-257.

Hayes KC \& Khosla P (1992) Dietary fatty acid thresholds and cholesterolemia. FASEB Journal 6, 2600-2607.

Hegsted DM, McGandy RB, Myers ML \& Stare FJ (1965) Quantitative effects of dietary fat on serum cholesterol in man. American Journal of Clinical Nutrition 17, 281-295.

Horton JD, Cuthbert JA \& Spady DK (1993) Dietary fatty acids regulate hepatic low density lipoprotein (LDL) transport by altering LDL receptor protein and mRNA levels. Journal of Clinical Investigation 92, 743-749.

Innis SM, Quinlan P \& Diersen-Schade D (1993) Saturated fatty acid chain length and positional distribution in infant formula: effects on growth and plasma lipids and ketones in piglets. American Journal of Clinical Nutrition 57, 382-390.

Jensen RG (1996) The lipids in human milk. Lipids Research 35, 53-92.

Jensen RG, Ferris AM, Lammi-Keefe CJ \& Henderson RA (1990) Lipids of bovine and human milks: a comparison. Journal of Dairy Science 73, 223-240.

Keys A \& Parlin RW (1966) Serum cholesterol response to changes in dietary lipids. American Journal of Clinical Nutrition 19, 175-181.

Khosla P, Hajri T, Pronczuk A \& Hayes KC (1997) Decreasing dietary lauric and myristic acids improves plasma lipids more favorably than decreasing palmitic acid in rhesus monkeys fed AHA step 1 type diet. Journal of Nutrition 127, 525S-530S.

Kosarsky KF, Donahee MH, Rigotti A, Iqbal SN, Edelman ER \& Krieger M (1997) Overexpression of the HDL receptor SR-BI alters plasma HDL and bile cholesterol levels. Nature 387, 414-417.

Kovanen PT, Brown MJ \& Goldstein JL (1979) Increased binding of low density lipoprotein to liver membranes from rats treated with $17 \alpha$-ethinyl estradiol. Journal of Biochemical Chemistry 254, 11367-11373.

Kris-Etherton PM \& Dietschy J (1997) Design criteria for studies examining individual fatty acids effects on cardiovascular disease risk factors: human and animal studies. American Journal of Clinical Nutrition 65S, 159S-166S.

Kris-Etherton PM \& Yu S (1997) Individual fatty acid effects on plasma lipids and lipoproteins: human studies. American Journal of Clinical Nutrition 65, 1628S-1644S.

Kushwaha RS, Guntupalli B, Rice KS, Carey KD \& McGill HC (1995) Effect of dietary cholesterol and fat on the expression of hepatic sterol 27-hydroxylase and other hepatic cholesterol-responsive genes in baboons (papio species). Arteriosclerosis Thrombosis and Vascular Biology 15, 1404-1411.

Lindsey S, Benattar J, Pronczuk A \& Hayes KC (1990) Dietary palmitic aid (16:0) enhances high density lipoprotein cholesterol and low density lipoprotein receptor mRNA abundance in hamsters. Proceedings of the Society of Experimental Biology and Medicine 195, 261-269.

Lopez D \& McLean M (1999) Sterol regulatory element binding protein-1a binds to cis element in the promoter of the rat high density lipoprotein receptor SR-BI gene. Endocrinology 140, 5669-5681.

Lowry OH, Rosebrough NJ, Farr AL \& Randall RJ (1951) Protein measurement with Folin phenol reagent. Journal of Biochemical Chemistry 192, 265-275.

Lutton C (1990) Cholesterol and bile acids dynamics: comparative aspects. Reproduction Nutrition Development 30, 145-160.

Marrapodi M \& Chiang JYL (2000) Peroxisome proliferator activated receptor $\alpha(\mathrm{PPAR} \alpha)$ and agonist inhibit cholesterol $7 \alpha$ hydroxylase gene (CYP7A1) transcription. Journal of Lipid Research 41, 514-520.

Mensink RP (1993) Effects of the individual saturated fatty acids on serum lipids and lipoproteins concentrations. American Journal of Clinical Nutrition 57, S711-S714.

Milliat F, Grippois D, Blouquit MF, Ferezou J, Serougne C, Fidge NH \& Lutton C (2000) Short and long-term effects of steptozotocin on dietary cholesterol absorption, plasma lipoproteins and liver lipoprotein receptors in rico rats. Experimental and Clinical Endocrinology and Diabetes 108, 436-446.

Mizutani T, Yamada K, Minegishi T \& Miyamoto K (2000) Transcriptional regulation of rat scavenger receptor class B type I gene. Journal of Biochemical Chemistry 275, 22512-22519.

Nelson CM \& Innis SM (1999) Plasma lipoprotein fatty acids are altered by the positional distribution of fatty acids in infant formula triacylglycerols and human milk. American Journal of Clinical Nutrition 70, 62-69.

Nicolosi RJ (1997) Dietary fat saturation effects on low-density lipoprotein concentrations and metabolism in various animal models. American Journal of Clinical Nutrition $\mathbf{6 5}$, $1617 \mathrm{~S}-1627 \mathrm{~S}$.

Patel DD, Knight BL, Soutar A, Gibbons GF \& Wade DP (2000) The effect of peroxisome-proliferator-activated receptor $\alpha$ on the activity of the cholesterol $7 \alpha$ gene. Biochemical Journal 351, 747-753.

Philipp BW \& Shapiro DJ (1979) Improved method for the assay and activation of 3-hydroxy-3-methylglutaryl CoA reductase. Journal of Lipid Research 20, 588-593.

Rader DJ \& Maugeais C (2000) Genes influencing HDL metabolism: new perspectives and implications for atherosclerosis prevention. Molecular Medicine Today April, 170-175.

Rigotti A, Trigatti B, Penmam M, Ray-Burn H, Herz J \& Krieger M (1997) A targeted mutation in the murine gene encoding the HDL receptor scavenger receptor class B type I reveals its key role in HDL metabolism. Proceedings of the National Academy of Sciences USA 94, 12610-12615.

Salter AM, Mangiapane EH, Bennet AJ, Bruce JS, Billet MA, Anderton KL, Marenah CB, Lawson N \& White DA (1998) The effect of different dietary fatty acids on lipoprotein metabolism: concentration-dependent effects of diet enriched in oleic, myristic, palmitic and stearic acids. British Journal of Nutrition 79, 195-202.

Schneider WJ, Beisiegel U, Goldstein JL \& Brown MS (1982) Purification of the low density lipoprotein receptor, on acidic 
glycoprotein of 164000 molecular weight. Journal of Biochemical Chemistry 257, 2664-2673.

Small DM (1991) The effects of glyceride structure on absorption and metabolism. Annual Review of Nutrition 11, 413-434.

Snook JT, Williams G, Tsai YH \& Lee N (1999) Effect of synthetic triglyceride of myristic, palmitic and stearic acid on serum lipoprotein metabolism. European Journal of Clinical Nutrition 53, 597-605.

Souidi M, Parquet M \& Lutton C (1998) Improved assay of hepatic microsomal cholesterol $7 \alpha$-hydroxylase activity by use of hydroxyl- $\beta$-cyclodextrin and an NADPH regenerating system. Clinica Chimica Acta 269, 201-217.

Souidi M, Parquet M, Férézou J \& Lutton C (1999) Modulation of cholesterol $7 \alpha$ hydroxylase and sterol 27 -hydroxylase activities by steroids and physiological conditions in hamster. Life Science 64, 1585-1593.

Spady DK \& Dietschy JM (1983) Sterol synthesis in vivo in 18 tissues of the squirrel monkey, guinea pig, rabbit, hamster and rat. Journal of Lipid Research 24, 303-315.

Spady DK \& Dietschy JM (1988) Interaction of dietary cholesterol and triglycerides in the regulation of hepatic low-density lipoprotein transport in the hamster. Journal of Clinical Investigation 81, 300-309.

Spady DK, Kearney DM \& Hobbs HH (1999) Polyunsaturated fatty acids up-regulate hepatic scavenger receptor B1 (SRB1) expression and HDL cholesteryl ester uptake in the Hamster. Journal of Lipid Research 40, 1384-1394.

Stein O \& Stein Y (1999) Atheroprotective mechanisms of HDL. Atheroslerosis 144, 285-301.

Temme EHM, Mensink RP \& Hornstra G (1997) Effects of medium chain fatty acids (MCFA), myristic acid, and oleic acid on serum lipoprotein in healthy subjects. Journal of Lipid Research 38, 1746-1754.

Tholstrup T, Marckmann P, Jespersin J, Vessby B, Jart A \& Sandstrom B (1994) Effect on blood lipids, coagulation, and fibrinolysis of a fat high in myristic and a fat high in palmitic acid. American Journal of Clinical Nutrition 60,919-925.
Tsai YH, Park S, Kosavic J \& Snook JT (1999) Mechanisms mediating lipoprotein responses to diets with medium-chain triglyceride and lauric acid. Lipids 34, 895-905.

Varban ML, Rinninger F \& Wang N (1998) Targeted mutation reveals a central role for SR-BI in hepatic selective uptake of high density lipoprotein cholesterol. Proceedings of the National Academy of Sciences USA 95, 4619-4625.

Vlahcevic ZR, Jairah SK, Heuman DM, Stravitz RT, Hylemon PB, Avadhani NG \& Pandak WM (1996) Transcriptional regulation of hepatic sterol 27-hydroxylase by bile acids. American Journal of Physiology 270, G646-G652.

Von Eckardstein A \& Assmann G (2000) Prevention of coronary heart disease by raising high-density lipoprotein cholesterol? Current Opinion in Lipidology 11, 627-637.

Wang N, Arai T, Ji Y, Rinninger F \& Tall AR (1998) Liverspecific overexpression of SR-BI decreases levels of VLDL Lipoprotein apoB, LDL lipoprotein apoB and HDL lipoprotein in transgenic mice. Journal of Biochemical Chemistry 273, 32920-32926.

Weigand KW \& Daggy PB (1990) Quantification of high-density cholesterol in plasma from hamsters by differential precipitation. Clinical Chemistry 36, 575.

Woolett LA, Spady DK \& Dietschy JM (1992) Regulatory effects of the saturated fatty acids 60 through 180 on hepatic low density lipoprotein receptor activity in the hamster. Journal of Clinical Investigation 89, 1133-1141.

Worgall TS, Shurley SL, Seo T, Osborne TF \& Deckelbaum RJ (1998) Polyunsaturated fatty acids decrease expression of promoters with sterol regulatory elements by decreasing levels of mature sterol regulatory element binding protein. Journal of Biochemical Chemistry 273, 25537-25540.

Zock PL, De Vries JHM, De Fouw NJ \& Katan MB (1995) Positional distribution of fatty acids in dietary triglycerides: effects on fasting blood lipoprotein concentrations in humans. American Journal of Clinical Nutrition 61, 48-55. 